\title{
Rey Complex Figure Test and the evaluation of executive functions in children and adolescents
}

\section{Josefina Rubiales - Daiana Russo - Micaela Reyna}

Instituto de Psicología Básica, Aplicada y Tecnología (IPSIBAT), Universidad Nacional de Mar del Plata, Facultad de Psicologia, Consejo Nacional de Investigaciones Cientificas y Técnicas (CONICET), Mar del Plata, Argentina.

DOI: http://dx.doi.org/10.7358/neur-2018-024-rubi～josefinarubiales@gmail.com

\section{ABSTRACT}

Objective: The aim of this study was to analyze which aspects of the Rey Complex Figure Test are more sensitive to the Executive Functions in children and adolescents. Methodology: The study employed a non-experimental cross-sectional design, of retrospective ex-post facto type with one group. The study worked with a purposive sample of 97 children and adolescents between the ages of 8 and 14. To meet the study's objectives, researchers administered the Rey Complex Figure Test, the Mexican Pyramids and Backwards Digit Span subtests of the ENI Battery, the Wisconsin Card Sorting Test and the Stroop Test. Results: significant correlations were found between the Rey Complex Figure Test and executive functions performance. Conclusions: there is evidence that the Rey Complex Figure Test is a measure that, in addition to measuring visuoconstructional abilities and visual memory, provides information about executive performance of children and adolescents linked to the functions of cognitive flexibility, organization and working memory.

Keywords: Rey Complex Figure Test; executive functions; children; adolescents 


\section{INTRODUCTION}

The Rey Complex Figure Test (RCFT) is a classic neuropsychological instrument that evaluates visuoconstructional abilities and visual memory, and, at the same time, involves planning and organizational skills (Da Silva, Peçanha, CharchatFichman, Oliveira, \& Correa, 2016; Meyers, 1995; Senese, De Lucia, \& Conson, 2015; Strauss, Shermann, \& Spreen, 2006). It was designed by André Rey in 1941, and a scoring system was later developed by Osterrieth (1944) to standardize the original procedure. Given the complexity of the figure, it is also widely held to reflect the cognitive processes involved in devising organizational strategies to copy the figure and, therefore, it is regarded as a useful tool to evaluate cognitive functioning (Watanabe et al., 2005).

Research on Executive Functions (EFs) and their disorders has been on the rise in recent decades. EFs are defined as cognitive and emotional abilities involved in resolving novel situations; they are needed to establish objectives, plan and initiate activities, self-regulate and monitor tasks, select behaviors and execute actions to achieve the objectives (Ardila, Pineda, \& Rosselli, 2000; Diamond, 2013; Lezak, Howieson, \& Loring, 2004; Verdejo-García \& Bechara, 2010). EFs are mediated by dynamic and flexible networks. Their neuroanatomical base is in the prefrontal cortex and they have reciprocal connections with other regions of the cerebral cortex and subcortical structures (Verdejo-García \& Bechara, 2010).

The evolution of EFs in infancy is vital to proper cognitive functioning and to a child's academic, social and emotional development (Sastre-Riba, MerinoMoreno, \& Poch-Olivé, 2007). This evolution involves the development of a series of cognitive abilities that allows a child to store information, manipulate it and act on it, as well as to self-regulate behavior and adapt it to changes in the environment (García-Molina, Enseñat-Cantallops, Tirapu-Ustárroz, \& Roig-Rovira, 2009). Hence, early disturbances in the development of executive development can have several short-, medium- and long-term consequences (García-Molina et al., 2009). The prefrontal cortex is the newest area of the brain and the most vulnerable. The FE can be affected in situations of stress, sadness, loneliness, sleep deprivation or poor physical health. And these failures in the FE can cause learning problems in the school, social problems and behavioral problems with a poorer reasoning and problem solving, forgetting things and impaired ability to exercise self-control (Diamond, 2013; Diamond \& Ling, 2016).

In recent years, researchers have attempted to define the EF construct, and have identified various components. In this respect, Miyake, Friedman, Emerson, Witzki and Howerter (2000) propose the empirical division of three main executive components: working memory, inhibition and cognitive flexibility. These authors develop the idea of EF unity and diversity, suggesting that EFs share underlying features or abilities (which confers them a certain degree of unity), while at the 
same time being separable and contributing differentially to individual performance in goal-oriented tasks. These EF components are described below:

Working memory: involves the ability to simultaneously store and process information in the short-term that is relevant to achieving a goal (Baddeley, 2012). Thus it makes possible the temporary storage and mental manipulation of information that is verbal or spatial visual in nature and not perceptual at the moment (Diamond, 2013).

Cognitive flexibility: is defined as the ability to quickly alternate from one response to another, to change to more effective strategies, and to divide one's attention in the face of the changing demands of a task or situation (Anderson, 2002). It is the executive process responsible for generating changes in behavior and ways of thinking in dynamic contexts (Diamond, 2013).

Inhibition: refers to the ability to impede interference from irrelevant information when responding, and to suppress information that was previously relevant but is not currently useful (Carlson \& Wang, 2007; Sabagh Sabbagh, 2008). It is the mechanism that reduces interference and checks the prepotent tendencies that may present themselves in the areas of thinking, behavior and the environment (Diamond, 2013).

Although working memory, inhibition and cognitive flexibility are generally accepted as the main EFs, other EFs based on these are considered to be of a higher-order; planning is one of them (Diamond, 2013). Planning is a cognitive ability that involves anticipating the result of a response, which in turn involves considering different courses of action and choosing that which is most pertinent considering the consequences of the possible actions (Tirapu-Ustárroz, MuñozCéspedes, Pelegrín-Valero, \& Albéniz-Ferreras, 2005). Consequently, this generates additional demands on the processes of inhibition (since it involves the selection of one alternative and the inhibition of others) and working memory (since it requires the proper functioning of operational memory in general and the ability to maintain attention (Papazian, Alfonso, \& Luzondo, 2006; Soprano, 2003), and more specifically the central executive system, involving a more complex step than these processes individually (Tirapu-Ustárroz et al., 2005). Por estos motivos es considerada una FE de orden superior, being synonymous of the subcomponents of reasoning and problem solving of the FE (Diamond, 2013).

To date, studies on the RCFT have considered the test as a useful measure of $\mathrm{EF}$ evaluation, however, have reported inconsistent results regarding which aspects of the TFCR that are specifically related to EF. Diverse studies provide evidence in favor of RCFT as a useful EF evaluation measure (Anderson, Anderson, \& Garth, 2001; Beebe, Ris, Brown, \& Dietrich, 2004; Davies, Field, Andersen, \& Pestell, 2011; Martens, Hurks, \& Jolles, 2014; Ogino et al., 2009; Somerville, Tremont, \& Stern, 2000; Watanabe et al., 2005). These studies found significant correlations between various tests that evaluate EFs and different RCFT scoring systems: The 
Rey Complex Figure Organizational Strategy Score (RCF-OSS); Development Scoring System Storage (DSS) and the Boston Qualitative Scoring System (BQSS). These scoring systems have been developed to evaluate planning and organization strategies during the reproduction process.

Anderson and colleagues (2001) used the RCF-OSS scoring system and found moderate correlations with tests that evaluated planning and organization and flexibility. Additionally, the results reflected the expected increases in RCFOSS performance by age group (children from the ages of 7 to 13) in terms of precision, memory and organization level, which implies the development of a set of cognitive abilities. Martens and colleagues (2014) with the same scoring system, found correlations with functions such as fluency, working memory and reasoning. Beebe and colleagues (2004) found significant, albeit moderate, correlations between the DSS-scored RCFT and WISC III's Block Design subtest in adolescents between 14 and 16 years of age; however, this study reported that correlations with tests that evaluate flexibility and sustained attention were not found. Lastly, Somerville and colleagues (2000) as well as Watanabe and colleagues (2005) used the BQSS. Somerville and colleagues (2000) conducted their research on adult patients and found significant correlations with tasks to evaluate cognitive flexibility, verbal fluency an working memory. And Watanabe and colleagues (2005), who conducted their research on children between 5 and 14 years of age, found correlations between the BQSS and performance on tests that evaluate flexibility, organization and planning, and working memory. In this study, significant correlations with tests that evaluate inhibition were not found, and the authors concluded that inhibitory control is minimally involved in RCFT performance scored with the BQSS.

It is important to mention that Weber, Riccio and Cohen (2013) do not consider the RCFT as an EF evaluation measure. They did not find significant correlations with tests that assess these functions. The authors did find correlations with tests to evaluate visual motor integration and cognitive abilities in general. It should be noted that this study used the Meyers and Meyers scoring system, which was designed to evaluate the precision of detail in the reproduction of the figure.

What stands out in this review of the literature is the need to conduct further studies that correlate the RCFT with other measures of executive functioning to explore how much the RCFT's copy strategies evaluate executive functions, and in particular, the planning function in children and adolescents (Da Silva et al., 2016). Accordingly, the aim of this study was to analyze which aspects of the Rey Complex Figure Test are more sensitive to the Executive Functions in children and adolescents. 


\section{METHOD}

\subsection{Type of study}

Non-experimental, cross-sectional, of type retrospective ex post-facto with one group, as per the classification proposed by Montero and León (2007).

\subsection{Participants}

The study used an intentional sample of 97 children and adolescents $(54.6 \%$ male and $45.4 \%$ female) from 8 to 14 years of age $(M=10.88 ; S D=1.69)$ enrolled in school in the City of Mar del Plata, Argentina, which were selected via random sampling, divided into 2 samples by age ( 58 children from 8 to 11 years old and 39 adolescents from 12 to 14 years old). The sample included children and adolescents of regular mainstream schools, without difficulty in learning difficulties and in the intellectual level $(M=95,05 ; D E=11,82)$, and no history of neurological or psychiatric conditions, or learning disabilities.

\subsection{Instruments}

The study used the Rey Complex Figure Test (Rey, 1997) to evaluate the reproduction process and organization strategies. This test consists of copying a complex geometric drawing. The child is to copy the drawing, with the original drawing available for reference, using a different colored pencil every 45 seconds, which allows researchers to distinguish 6 timeframes corresponding to each color, in which were scored the percentage of elements that were drawn for each time.

Further, the study used two scoring methods developed by Osterrieth (1944) to calculate score totals for copying and type of reproduction. First, the figure was subcategorized into 18 parts, which were scored based on location and precision: correct element in right place $=2$ points; correct element in wrong place $=1$ point; deformed or incomplete element in right place $=1$ point; deformed or incomplete element in wrong place $=0.5$ of a point; and absent $=0$ points.

Second, the figure was analyzed based on reproduction type according to the description manual (Rey, 1997): (I) Construction on frame; (II) Details within in the frame; (III) General outline; (IV) Detail juxtaposition; (V) Details on confusing background; (VI) Reduction to a familiar outline; and (VII) Scribble. In the present study, the reproduction types were codified as follows: Type A (groups together Type I and II); Type B (corresponds to Type III); Type C (corresponds to Type IV); Type D (corresponds to Type V) and Type E (corresponds to Type VI).

Lastly, in order to analyze the organization strategy used to copy the figure, this 
study used a procedure based on the one created by Stern and colleagues (1999), the Boston Qualitative Scoring System (BQSS), which breaks the figure up into three sets of elements (Configural Elements (CE), Clusters, and Details). The present study analyzed the percentage of elements drawn in each one of the three sets. A score was calculated based on the number of elements in each set $(\mathrm{CE}=6$ elements; Clusters $=10$ elements; Details $=6$ elements).

For the TFCR score, a reliability study of the coding process between evaluators was carried out. The method implemented consisted of two researchers scored the test independently in a random sample of $20 \%$ of the total cases. A degree of agreement was obtained around $90 \%$, which is highly satisfactory (Orwin, 1994), and the differences between the evaluators were resolved by consensus.

Executive functioning was evaluated by administering the following instruments:

The Mexican Pyramid subtest of the Children's Neuropsychological Battery (ENI) (Matute, Roselli, Ardila \& Ostrosky-Solis, 2007) (r=0.24) was used to evaluate organization and planning. The subtest consists of organizing three cubes of different colors and sizes according to 11 designs requested, which requires planning and organizing plans of action to meet the goal.

The Backwards Digit Span of the Children's Neuropsychological Battery (Batería Neuropsicológica Infantil (ENI)) (Matute et al., 2007) (r=0.44) was administered to evaluate working memory. The test involves having a child repeat a series of numbers in reverse order.

The Wisconsin Card Sorting Test (Heaton, Chelune, Talley, Kay, \& Curtis, 1997) ( $\mathrm{r}=0.9)$ was applied to evaluate cognitive flexibility. It consists in a classification of cards where the child must determine the underlying sorting principle (color, shape, number) of the classification, with feedback (correct or incorrect) from an evaluator.

And the Stroop Color and Word Test (Golden, 1994) ( $\mathrm{r}=0.82$ ) was administered to evaluate cognitive inhibition. The Test consists of three parts: in the first, the reading speed is evaluated, where the child must read the names of the colors red, green and blue, printed in black; in the second, the speed in naming colors is evaluated, where the child has the name of the colors printed in each row of ' $x$ '; and the third contains the colors red, green and blue, printed with a different color from the written word, so the child must name the color of the ink with which it is printed by the word ignoring the meaning. The interference that is generated in the third sheet is known as the "Stroop effect" (Soprano, 2009), and the score is the most important of the test to analyze the inhibition, allows to evaluate the resistance to the interference generated, the cognitive inhibition capacity. 


\subsection{Procedure}

The present study was conducted as part of a larger research project under the auspices of the Human Behavior, Genetics and Environment (Comportamiento Humano, Genética y Ambiente) Research Group, IPSIBAT (Instituto de Psicología Básica, Aplicada y Tecnología), CONICET (Consejo Nacional de Investigaciones Científicas y Técnicas), approved by the Secretariat of Science and Technology, National University of Mar del Plata (UNMdP), Argentina. In order to comprise the study's sample, contacts were established with educational institutions in the city of Mar del Plata, and these were informed as to the objectives and procedures of the present study. Then, in a sealed envelope, parents were mailed an informed consent form and each child was explained the objectives of the study and the confidentiality of the data. Thus, participation was voluntary and subject to the assent of the participating children and the informed consent of their parents. The evaluation was conducted individually at the educational institutions and during school hours. The instruments were administered by specialized professionals, who are also members of the research group. Throughout the study, researchers respected the ethical principles that govern research with human subjects, ensuring the necessary conditions to protect confidentiality and act for the benefit of participants.

\subsection{Statistical analysis}

The statistical analysis was realized using SPSS (Statistical Package for the Social Sciences), version 19. To meet the study's objectives, descriptive statistical analysis was conducted (average, SD and frequency) as well as correlation analysis.

\section{RESULTS}

Descriptive statistical analyses were conducted to show performance on the RCFT and EF tests; for the total sample and by age groups (children and adolescents), and then was made a comparison of means between both age groups. The results of the analyzed variables are presented in Table 1. 
Table 1. Descriptive analysis of Rey Complex Figure and EF tests and Student's t test with the effect size

\begin{tabular}{|c|c|c|c|c|c|c|}
\hline \multicolumn{2}{|c|}{ Test } & Tot & Children & Adolescents & $t$ test & \multirow[t]{2}{*}{$d^{\prime}$} \\
\hline & & Average(SD) & Average(SD) & Average(SD) & Sig. (t) & \\
\hline Cogn. & $\mathrm{C}$ & $75.30(14.73)$ & $74.87(10.27)$ & 75.61(17.37) & $.80(-.24)$ & .05 \\
\hline \multirow[t]{5}{*}{ Flex. } & E & $24.30(12.12)$ & $25.22(10.27)$ & $23.63(13.36)$ & $.52(.63)$ & .13 \\
\hline & CAT & $2.49(.76)$ & $2.53(.74)$ & $2.46(.78)$ & $.64(.45)$ & .09 \\
\hline & $\mathrm{P}$ & $13.80(8.24)$ & $13.83(7.64)$ & $13.78(8.72)$ & $.97(.03)$ & .00 \\
\hline & PE & $12.61(7.13)$ & $12.93(6.28)$ & $12.37(7.75)$ & $.70(.38)$ & .08 \\
\hline & CL & $65.47(19.20)$ & $66.28(16.33)$ & $64.90(21.14)$ & $.73(.34)$ & .07 \\
\hline Inhib. & I & 49.31(8.00) & 49.70(6.87) & $49.03(8.79)$ & .68(.40) & .08 \\
\hline \multirow[t]{3}{*}{ Org. } & NM & $59.99(7.23)$ & $59.41(5.86)$ & $60.41(8.11)$ & $.50(-.66)$ & .14 \\
\hline & $\mathrm{CD} / \mathrm{MN}$ & $8.55(1.58)$ & $8.51(1.58)$ & $8.57(1.60)$ & $.85(-.18)$ & .03 \\
\hline & $\mathrm{T}$ & $90.43(25.76)$ & $97.78(24.62)$ & $85.05(25.45)$ & $.01 *(2.46)$ & .51 \\
\hline WM & BD & $4.81(1.48)$ & $4.32(1.42)$ & $5.18(1.44)$ & $.00 *(-2.92)$ & .60 \\
\hline \multirow[t]{15}{*}{ RCFT } & CR & $23.92(5.61)$ & $21.35(5.55)$ & $25.81(4.89)$ & $.00^{*}(-4.18)$ & .84 \\
\hline & Type A & $.12(.33)$ & $.10(.30)$ & $.14(.35)$ & $.50(-.66)$ & .00 \\
\hline & Type B & $.11(.31)$ & $.10(.30)$ & $.13(.33)$ & $.67(-.41)$ & .09 \\
\hline & Type C & $.70(.46)$ & $.73(.44)$ & $.68(.47)$ & $.57(.56)$ & .11 \\
\hline & Type D & $.05(.22)$ & $.07(.26)$ & $.04(.18)$ & $.41(.81)$ & .13 \\
\hline & Type E & $.01(.10)$ & $.00(.00)$ & $.02(.13)$ & $.39(-.85)$ & .12 \\
\hline & Time 1 & $16.93(9.59)$ & $15.56(7.37)$ & $17.94(10.89)$ & $.23(-1.20)$ & .26 \\
\hline & Time 2 & $15.75(10.52)$ & $17.18(11.11)$ & 14.71(10.04) & $.25(1.14)$ & .23 \\
\hline & Time 3 & $19.34(9.49)$ & $17.42(8.55)$ & $20.74(9.96)$ & $.08(-1.72)$ & .36 \\
\hline & Time 4 & $16.69(10.31)$ & $16.38(10.04)$ & $16.92(10.58)$ & $.79(-.25)$ & .05 \\
\hline & Time 5 & $8.39(9.71)$ & $8.47(9.19)$ & $8.33(10.16)$ & $.94(.07)$ & .01 \\
\hline & Time 6 & $3.48(9.51)$ & $2.67(8.45)$ & $4.08(10.25)$ & $.47(-.72)$ & .15 \\
\hline & CE & $78.52(24.17)$ & $71.13(25.00)$ & $83.92(22.23)$ & $.00 *(-2.65)$ & .53 \\
\hline & Cluster & $89.46(13.25)$ & $88.89(12.90)$ & $89.88(13.61)$ & $.71(-.36)$ & .07 \\
\hline & Details & $69.41(23.40)$ & $67.48(26.07)$ & $70.83(21.37)$ & $.48(-.69)$ & .13 \\
\hline
\end{tabular}

Key: Cogn.Flex=Cognitive flexibility (Wisconsin Card Sorting Test): C. Correct; E. errors; CAT. categories; P. Perseveration; PE. perseverative errors; CL. conceptual level; Inhibition (Stroop Test): I. interference; Org. (Organization=Mexican Pyramid): NM. number of moves; CD/MN. correct design/minimum number of moves; T. time. WM. Working Memory (Backwards Digit Span): BD. backward digit. RCFT: CR. complete reproduction; CE. configural elements

Table 1 shows few statistically significant differences with respect to age, only for working memory $(\mathrm{p}=.00)$, the time taken in the Mexican Pyramid $(\mathrm{p}=.01)$, which is lower in adolescents, the percentage of CE $(\mathrm{p}=.00)$ and the CR in RCFT $(\mathrm{p}=.00)$ that are older in adolescents with respect to children. In the flexibility and inhibition, no differences are observed with respect to age.

And a correlational analysis was conducted for the purpose of analyzing the relationships between the RCFT and EF tests. The results are presented in Table 2. 
Table 2. Correlational analysis between RCFT and EF tests

\begin{tabular}{|c|c|c|c|c|c|c|c|c|c|c|c|}
\hline & \multicolumn{6}{|c|}{ Cognitive Flexibility } & nhibition & \multicolumn{3}{|c|}{ Organization } & \multirow{2}{*}{$\frac{\mathrm{WM}}{\mathrm{BD}}$} \\
\hline & $\mathrm{C}$ & $\mathrm{E}$ & CAT & $\mathrm{P}$ & $\mathrm{PE}$ & CL & I & NM & $\mathrm{CD} / \mathrm{MN}$ & $\mathrm{T}$ & \\
\hline CR & .17 & $.00^{*}$ & .52 & $.02^{*}$ & $.01^{*}$ & .15 & .84 & .36 & .83 & $.00^{*}$ & $.03^{*}$ \\
\hline Type A & .20 & .13 & .67 & .38 & .32 & $.04^{*}$ & .41 & .25 & .38 & .17 & .51 \\
\hline Type B & .82 & .88 & .52 & .31 & .45 & .37 & .18 & .59 & .55 & .54 & .68 \\
\hline Type C & .15 & .80 & .29 & .58 & .83 & .58 & .81 & $.04^{*}$ & .10 & .09 & .84 \\
\hline Type D & .53 & .11 & .75 & .15 & $.04^{*}$ & .48 & .38 & .07 & .28 & $.02^{*}$ & .78 \\
\hline Type E & .81 & .80 & .51 & .67 & .70 & .85 & .48 & .78 & .73 & .99 & .58 \\
\hline Time 1 & $.04^{*}$ & .44 & .10 & .89 & .84 & .11 & .75 & .59 & .84 & .09 & .71 \\
\hline Time 2 & .45 & .31 & .20 & .30 & .38 & .40 & .09 & .17 & .94 & .26 & .22 \\
\hline Time 3 & .09 & .22 & .26 & .24 & .27 & .53 & .44 & .43 & .11 & .09 & .68 \\
\hline Time 4 & .39 & .43 & .94 & .49 & .82 & .37 & .43 & .48 & .96 & .19 & .85 \\
\hline Time 5 & .81 & .57 & .18 & .93 & .88 & .39 & .63 & .32 & .67 & .56 & .94 \\
\hline Time 6 & .31 & .69 & .19 & .41 & .48 & .56 & .53 & .75 & .27 & .44 & $.02^{*}$ \\
\hline CE & .69 & .21 & .99 & .36 & .23 & .71 & .55 & .33 & .62 & $.00^{*}$ & $.02^{*}$ \\
\hline Cluster & .69 & .08 & .47 & .12 & .11 & .98 & .40 & .80 & .78 & $.01^{*}$ & .65 \\
\hline Details & .88 & .66 & .13 & .42 & .63 & .22 & .38 & .39 & .63 & .24 & .21 \\
\hline
\end{tabular}

Key: Cognitive flexibility: C. Correct; E. errors; CAT. categories; P. Perseveration; PE. perseverative errors; CL. conceptual level; Inhibition: I. interference; Organization: NM. number of moves; CD/MN. correct design/minimum number of moves; T. time. WM. Working Memory: BD. backward digit. RCFT: CR. complete reproduction; CE. configural elements

With respect to the cognitive flexibility test (WCST), there is a negative correlation between the RCFT's complete reproduction score and certain WCST scores; in other words, the better the performance on the RCFT, the fewer the errors, perseverative responses and perseverative errors in the WCST.

With respect to RCFT reproduction times, Time 1 correlated negatively with correct reproductions. And further analysis shows that the $\%$ of elements in the cluster set reproduced in Time 1 and the \% of elements in the CE set reproduced in Time 3 correlate negatively with correct reproductions $(r=-.38, p=.00 ; r=-.28$, 
$\mathrm{p}=.00)$ and conceptual level responses $(\mathrm{r}=-.31, \mathrm{p}=.00 ; \mathrm{r}=-.22, \mathrm{p}=.03)$ on the WCST. In terms of the results in the inhibition test (Stroop Test), no correlations were found.

With respect to the test that evaluated organization and planning (Mexican Pyramids), the time spent on it correlated negatively with the RCFT's complete reproduction score. This is reflected in the correlations between time spent on the Mexican Pyramids and the number of elements reproduced in the RCFT's six timeframes. Negative correlations were found between the time spent on the Pyramids and the $\%$ of cluster elements in Time $1(\mathrm{r}=-.35 \mathrm{p}=.00)$, the $\%$ of detail elements in Time $1(\mathrm{r}=-.21 \mathrm{p}=.03)$, the $\%$ of configural elements in Time $2(\mathrm{r}=-.20$ $\mathrm{p}=.04)$, the $\%$ of configural elements in Time $3(\mathrm{r}=-.25 \mathrm{p}=.01)$, and the $\%$ of configural elements in Time $4(\mathrm{r}=-.20 \mathrm{p}=.04)$.

Additionally, negative correlations were also observed between the percentage of elements in the $\mathrm{CE}$ and cluster sets, and the time spent on the design in the Mexican Pyramids test.

Lastly, with respect to the test that evaluated working memory (Backward Digit Span), positive correlations were found between the items recalled from working memory and the following: complete reproduction in the RCFT; the total number of elements reproduced in Time 6; and the total number of elements reproduced in the $\mathrm{CE}$ set.

\section{DISCUSSION}

The RCFT has become one of the most widely applied neuropsychological tests, both in clinical and research settings. It has traditionally been used to evaluate visuoconstructional abilities when copying and drawing the figure from memory. However, recent studies have suggested that it might be useful in the evaluation of executive functions (Anderson et al., 2001; Beebe et al., 2004; Somerville et al., 2000; Watanabe et al., 2005). Yet, because the results in populations of children have been little bit conclusive, the aim of this study was to analyze which aspects of the Rey Complex Figure Test are more sensitive to the Executive Functions in children and adolescents. The study seeks to provide evidence of significant correlations between the RCFT and several executive functions, namely flexibility, organization and planning, and working memory, but not inhibition.

With respect to cognitive flexibility, it was observed that children who performed better on the RCFT presented greater cognitive flexibility and less cognitive rigidity. This coincides with the findings of previous studies (Anderson et al. 2001; Beebe et al., 2004; Somerville et al., 2000; Watanabe et 
al., 2005). Further, in terms of copying type, it was found that, on the one hand, Type A reproduction (reproduction of the frame and the inclusion of its details) was related with better performance at the conceptual level in cognitive flexibility in terms of comprehending principles of classification. On the other hand, Type D reproduction (reproduction of details on a confusing background) was related with a greater number of perseverative errors. In terms of the RCFT's reproduction timeframes, it was observed that reproducing a greater number of cluster elements at the start and a greater number of configural elements in Time 3 correlated with decreased cognitive flexibility performance.

In the test that evaluated organization and planning, it was found that when more time is spent in the construction of the designs, which implies difficulties in this function, there is inferior performance in RCFT reproduction. This is reflected throughout the copying process. Additionally, Type $\mathrm{C}$ reproduction (copying details by juxtaposition) is expected of children from 5 to 11 years of age (Rey, 1997), and was found to be associated with a lower number of moves to achieve the final objective in the Mexican Pyramids test, which implies good organization and planning performance. It should be noted that this function is one of the most widely analyzed and that there is ample evidence of its relation with the RCFT (Anderson et al., 2001; Beebe et al., 2004; Watanabe et al., 2005).

With respect to working memory, it was found that better performance in the reproduction of the figure was related to better performance in the evaluation of this function. This result coincides with the findings of Somerville and colleagues (2000), but contradicts the findings of Watanabe and colleagues (2005). The latter found significant correlations between the RCFT and a digit-span task, when the numbers are repeated in the same order, but not with a backwards digit-span task. It should be noted that a measure of working memory was not included in all of the previously mentioned studies in this area.

In contrast to the findings mentioned thus far, there was no significant correlation found between the inhibition test and the RCFT. Similar results were reported by Watanabe and colleagues (2005), who explained this finding by suggesting that inhibitory control was probably minimally involved in RCFT performance or not directly evaluated by the scoring system used.

In conclusion, the current study's results provide evidence that in addition to measuring visuoconstructional abilities and visual memory, the RCFT can also provide information on an individual's executive performance, evidencing aspects that are more sensitive to EF such as cognitive flexibility, working memory and organization.

It is possible that not conclusive results so far, can be due to the use of different scoring systems to evaluate the RCFT, since those studies that used the scoring systems specifically designed to evaluate planning and organization (Boston Qualitative Scoring System (BQSS), Developmental Scoring System 
(DSS), The Rey Complex Figure Organizational Strategy Score (RCF-OSS)) have, for the most part, provided evidence in favor of the RCFT as a useful measure of executive functioning, while those that have used scoring systems that evaluate other components, such as precision in copying the figure (Meyers and Meyers Scoring System) have indicated the absence of a correlation between the RCFT and executive functioning (Weber et al., 2013).

As limitations of this work the instruments selected to evaluate the executive functioning are mentioned; on the one hand, the Wisconsin Card Sorting Test which, although it is a test used to evaluate flexibility (Salvador, Cortés, Galindo, \& Villa, 2000), is a task of complex interpretation, since it not only evaluates the cognitive flexibility but can reflect multiple processes (Bishara et al., 2010), including the participation of other functions linked to planning strategies, organized inquiries, use of environmental feedback to change schemas and modulation of impulsive responses (Heaton et al., 1997; Soprano, 2009), so it cannot be affirmed that it only evaluates cognitive flexibility; and on the other hand the Stroop Test, used to evaluate cognitive inhibition, includes the analysis of reading and selective attention, thus affecting the sensitivity of the test. These limitations could be avoided by incorporating additional test to allow assessment of flexibility and cognitive inhibition, like Tareas de Autorregulación Cognitiva Battery (Introzzi \& Canet Juric, 2013).

Based on the results and this discussion, it would be of interest for future studies to include tests of executive functioning with greater ecological validity that more precisely reflect a child's functioning in regular practice.

\section{REFERENCES}

Anderson, P. (2002). Assessment and development of executive function (EF) during childhood. Child Neuropsychology, 8(2), 71-82.

Anderson, P., Anderson, V., \& Garth, J. (2001). Assessment and development of organizational ability: The Rey Complex Figure Organizational Strategy Score (RCF-OSS). The Clinical Neuropsychologist, 15(1), 81-94.

Ardila, A., Pineda, D., \& Rosselli, M. (2000). Correlation Between Intelligence Test Scores and Executive Function Measures. Archives of Clinical Neuropsychology, 15(1), 31-36.

Baddeley, A. (2012). Working memory: theories, models, and controversies. Annual review of psychology, 63, 1-29. 
Beebe, D. W., Ris, M. D., Brown, T. M., \& Dietrich, K. N. (2004). Executive functioning and memory for the Rey-Osterreith complex figure task among community adolescents. Applied neuropsychology, 11(2), 91-98.

Bishara, A. J., Kruschke, J. K., Stout, J. C., Bechara, A., Mc Cabe, D. P., \& Busemeyer, J. R. (2010). Sequential Learning Models for the Wisconsin Card Sort Task: Assessing Processes in Substance Dependent Individuals. Journal of mathematical psychology, 54(1), 5-13.

Carlson, S. M. \& Wang, T. (2007). Inhibitory control and emotion regulation in preschool children. Cognitive Development, 22, 489-510.

Da Silva, A. M., Peçanha, E., Charchat-Fichman, H., Oliveira, R. M., \& Correa, J. (2016). Estratégias de cópia da Figura Complexa de Rey por Crianças. Neuropsicologia Latinoamericana, 8(1), 12-21.

Davies, S. R., Field, A. R., Andersen, T., \& Pestell, C. (2011). The ecological validity of the Rey-Osterrieth Complex Figure: Predicting everyday problems in children with neuropsychological disorders. Journal of clinical and experimental neuropsychology, 33(7), 820-831.

Diamond, A. (2013). Executive functions. Annual Review of Psychology, 64, 135-168.

Diamond, A., \& Ling, D. S. (2016). Conclusions about interventions, programs, and approaches for improving executive functions that appear justified and those that, despite much hype, do not. Developmental cognitive neuroscience, 18, 34-48.

García-Molina A, A., Enseñat-Cantallops, J., Tirapu-Ustárroz, T., \& Roig-Rovira. (2009). Maduración de la corteza prefrontal y desarrollo de las funciones ejecutivas durante los primeros cinco años de vida. Revista de Neurología, 48(8), 435-440.

Golden, C. (1994). Stroop Test de colores y palabras. Madrid: TEA.

Heaton, R., Chelune, G., Talley, J., Kay, G. \& Curtis, G. (1997). Test de clasificación de tarjetas de Wisconsin. Madrid: TEA.

Introzzi, I. \& Canet Juric, L. (2013) Tareas de Autorregulación Cognitiva. In Introzzi, I., Canet Juric,L., Comesańa, A., Andres, M. L. \& Richard's, M. (2013). Evaluación de la Autorregulación cognitiva y emocional. Presentación de un Programa. Revista Argentina de Ciencias del Comportamiento (suplemento), 1-11.

Lezak, M. D., Howieson, D. V., \& Loring, D. W. (2004). Neuropsychological Assessment. 4ed. New York: Oxford University Press. 
Martens, R., Hurks, P. P. M., \& Jolles, J. (2014). Organizational Strategy Use in Children Aged 5-7: Standardization and Validity of the Rey Complex Figure Organizational Strategy Score (RCF-OSS). The Clinical Neuropsychologist, 28(6), 954-973.

Matute, E., Rosselli, M., Ardila, A., \& Ostrosky-Solis, F. (2007). Evaluación neuropsicológica infantil. México: Manual Moderno.

Meyers, J. (1995). The Meyers scoring system for the Rey complex figure and the recognition trial: professional manual. Odessa: Florida.

Miyake, A., Friedman, N. P., Emerson, M. J., Witzki, A. H., \& Howerter, A. (2000). The Unity and Diversity of Executive Functions and Their Contributions to Complex "Frontal Lobe" Tasks: A Latent Variable Analysis. Cognitive Psychology, 41(1), 49-100.

Montero, I. \& León, O. (2007). A guide for naming research studies in Psychology. International Journal of Clinical and Health Psychology, 7(3), 847-862.

Ogino, T., Watanabe, K., Nakano, K., Kado, Y., Morooka, T., Takeuchi, A., ... \& Ohtuska, Y. (2009). Predicting executive function task scores with the Rey-Osterrieth Complex Figure. Brain and Development, 31(1), 52-57.

Orwin, R. G. (1994). Evaluating coding decisions. In H. M. Cooper \& L. V. Hedges (Dirs.), The Handbook of Research Sintesis (pp. 134-172). Nueva York: Sage.

Osterrieth, P. A. (1944). Le test de copie d'une figure complexe. Archives de psychologie, 30, 206-356.

Papazian, O., Alfonso, I., \& Luzondo, R. J. (2006). Trastornos de las funciones ejecutivas. Revista de Neurología, 42(3), 45-50.

Rey, A. (1997). Test de Copia y de Reproducción de Memoria de Figuras Geométricas Complejas. Madrid: TEA.

Sabagh Sabbagh, S. (2008). Solution of Written Arithmetic Problems and Inhibitory Cognitive Control. Universitas Psychologica, 7(1), 215-228.

Salvador, J., Cortés, J. F., Galindo, \& Villa, G. (2000). ¿Qué significado psicológico tiene la perseveración de los pacientes con esquizofrenia paranoide en el Wisconsin Card Sorting Test?. Salud Mental, 23(4), 28-37.

Sastre-Riba, S., Merino-Moreno, N., \& Poch-Olivé, M. L. (2007). Formatos interactivos y funciones ejecutivas en el desarrollo temprano. Revista de Neurología, 44(2), 61-65.

Senese, V. P., De Lucia, N., \& Conson, M. (2015). Cognitive Predictors of Copying and Drawing From Memory of the Rey-Osterrieth Complex Figure in 7-to 10-YearOld Children. The Clinical Neuropsychologist, 29(1), 118-132. 
Somerville, J., Tremont, G., \& Stern, R. A. (2000). The Boston qualitative scoring system as a measure of executive functioning in Rey-Osterrieth complex figure performance. Journal of clinical and experimental neuropsychology, 22(5), 613-621.

Soprano, A. M. (2003). Evaluación de las funciones ejecutivas en el niño. Revista de Neurología, 37(1), 44-50.

Soprano, A. M. (2009). Como evaluar la atención y las funciones ejecutivas en niños y adolescentes. Buenos Aires: Paidós.

Stern, R., Javorsky, D., Singer, E., Singer-Harris, N., Somerville, J., \& Duke, L. (1999). The Boston Qualitative Scoring System. Odessa, FL: Psychological Assessment Resources Inc.

Strauss, E., Sherman, E. M. S., \& Spreen, O. (2006). A Compendium of Neuropsychological Tests: Administration, Norms, and Commentary. New York: Oxford University Press.

Tirapu-Ustárroz, J., Muñoz-Céspedes, J. M., Pelegrín-Valero, C., \& AlbénizFerreras, A. (2005). Propuesta de un protocolo para la evaluación de las funciones ejecutivas. Revista de Neurología, 41(3), 177-186.

Verdejo-García, A., \& Bechara, A. (2010). Neuropsicología de las funciones ejecutivas. Psicothema, 22, 227-235.

Watanabe, K., Ogino, T., Nakano, K., Hattori, J., Kado, Y., Sanada, S., \& Ohtsuka, Y. (2005). The Rey-Osterrieth Complex Figure as a measure of executive function in childhood. Brain and Development, 27(8), 564-569.

Weber, R. C., Riccio, C. A., \& Cohen, M. J. (2013). Does Rey Complex Figure copy performance measure executive function in children?. Applied Neuropsychology: Child, 2(1), 6-12. 
